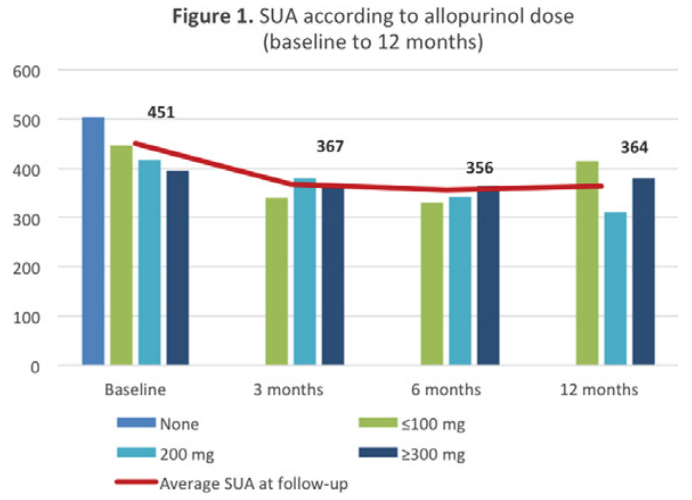

care between health care providers and providing outcomes data. With respect to effectiveness, findings show declining SUA over follow-up with over two-thirds of patients achieving target at the end of follow-up.

Disclosure of Interest: None declared

DOI: 10.1136/annrheumdis-2017-eular.4177

\section{THU0443 HYPERURICEMIA IS ASSOCIATED WITH INCREASED CORONARY ARTERY CALCIFICATION IN MEN BUT NOT WOMEN}

M.I. Dehlin ${ }^{1}$, P. Drivelegka ${ }^{1}$, V. Sigurdardottir ${ }^{1}$, O. Angerås ${ }^{2}$, L.T. Jacobsson ${ }^{1}$, H. Forsblad d'Elia ${ }^{1,3} \cdot{ }^{1}$ Dept of rheumatology and inflammation research, Institution of medicine, Sahlgrenska Academy, University of Gothenburg; ${ }^{2}$ Department of Cardiology, Sahlgrenska University Hospital, Gothenburg;

${ }^{3}$ Departments of Public Health and Clinical Medicine, Rheumatology, Umeå University, Umeå, Sweden

Background: Hyperuricemia is closely associated to cardiovascular disease although it has not been defintively established whether it is a marker or a causative agent. Serum uric acid (sUa) is strongly linked to the metabolic syndrome, hypertension ( $\mathrm{HT}$ ), dyslipidemia (DL) and higher BMI and higher levels are seen in men compared to women. Coronary artery calcification (CAC) is associated with future risk of atherosclerotic CV events in addition to these traditional cardiovascular risk factors (CVRF). CACs are present in atherosclerotic arteries and can be quantified and scored non-invasively by computed tomography. The Swedish CArdioPulmonarybiolmage Study (SCAPIS) extensively characterizes a Swedish cohort of 30000 men and women aged between 50 and 64 years. A comprehensive pilot study in 1111 individuals was completed in 2012. In this pilot study we have examined the relation between CACs and SUa

Objectives: Examine the association bewteen sUa and CAC in men and women seperately.

Methods: In the SCAPIS pilot study we identified 1106 (552 males) individuals who were screened for traditional CVDRFs, such as HT, DL, diabetes mellitus (DM), smoking, physical activity (PA), educational level (EDU), BMI, high sensitive CRP (hsCRP). CACs, reflecting calcification of coronary arteries, was determined according to Agatston ${ }^{1}$. We measured sUa and related quartiles to CACs with multiple logistic regression analyses adjusting for traditional CVDRFs. CAC was defined positive if $\geq 1$.

Table 1. Baseline characteristics of the study population divided by sex

\begin{tabular}{lcc}
\hline Variables & Male, $\mathrm{n}=552$ & Female, $\mathrm{n}=556$ \\
\hline Age, years, mean, (SD) & $57.8(4.5)$ & $57.6(4.3)$ \\
BMI, mean, (SD) & $27.7(4.0)$ & $26.9(3.7)$ \\
hsCRP, (mean, SD) & $2.3(3.3)$ & $2.4(3.7)$ \\
CAC positive, (\%) & $305(55 \%)$ & $142(26 \%)$ \\
Smoking status, never & $226(41 \%)$ & $249(45 \%)$ \\
Smoking status, previous & $242(44 \%)$ & $222(40 \%)$ \\
Smoking status, active & $82(15 \%)$ & $81(15 \%)$ \\
Hypertension (\%) & $178(32 \%)$ & $190(34 \%)$ \\
Diabetetes mellitus (\%) & $45(8 \%)$ & $23(4 \%)$ \\
Dyslipidemia (\%) & $160(29 \%)$ & $128(23 \%)$ \\
\hline
\end{tabular}

Table 2. Quartiles of sUa and age as predictors for presence of CAC (>0 CACs score) in male and female in multivariate logistic regression analyses adjusted for age, smoking, BMI, DM, DL, $\mathrm{HT}$, hsCRP, EDU and PA

\begin{tabular}{|c|c|c|c|c|c|}
\hline \multirow[t]{2}{*}{$\mathrm{sUa}, \mu \mathrm{mol} / \mathrm{L}$, } & \multicolumn{2}{|l|}{ Male } & \multirow[t]{2}{*}{$\mathrm{sUa}, \mu \mathrm{mol} / \mathrm{L}$} & \multicolumn{2}{|l|}{ Female } \\
\hline & $\begin{array}{c}\text { Odds ratio, } \\
\text { multivariate }^{\star},(\mathrm{Cl})\end{array}$ & $p$-value & & $\begin{array}{c}\text { Odds ratio, } \\
\text { multivariate }^{\star},(\mathrm{Cl})\end{array}$ & $p$-value \\
\hline 31-305, Ref & & & 143-229, Ref & & \\
\hline $306-350$ & $2.1(1.2-3.7)$ & 0.01 & $230-262$ & $0.9(0.5-1.7)$ & 0.7 \\
\hline $351-404$ & $1.8(1-3.3)$ & 0.04 & $263-305$ & $1(0.5-2)$ & 0.9 \\
\hline $405-665$ & $2(1-3.8)$ & 0.04 & $306-702$ & $1.2(0.6-2.3)$ & 0.6 \\
\hline \multicolumn{6}{|l|}{ Age 50-55, Ref } \\
\hline Age $56-60$ & $2.2(1.4-3.6)$ & 0.001 & & $3.6(2-6.5)$ & $<0.0001$ \\
\hline Age $61-66$ & $3.8(2.2-6.3)$ & $<0.0001$ & & $4.3(2.4-7.9)$ & $<0.0001$ \\
\hline
\end{tabular}

Results: Age, BMI, smoking status, hsCRP, HT and DL showed no differences between sex while presence of CAC and diabetes was twice as common in men (Table 1). The three upper quartiles of sUa, $(>306 \mu \mathrm{mol} / \mathrm{L})$, all significantly $(\mathrm{p}<0.05)$ predicted presence of CACs in men even adjusting for HT, DL, DM, smoking, PA, EDU, BMI, hsCRP and age in multivariate logistic regression, but not in women (Table 2).

Conclusions: Higher levels of $\mathrm{sUa}$ is associated with presence of CACs in men but not in women. This may merely reflect the earlier onset of atherosclerosis in men or possibly suggest biological differences in the effect of sUa on calcification of coronary arteries between sexes.

References:

[1] Agatston AS et al Quantification of coronary artery calcium using ultrafast computed tomography J Am Coll Cardiol 1990.

Disclosure of Interest: None declared

DOI: 10.1136/annrheumdis-2017-eular.2714

\section{THU0444 INTEGRATED SAFETY OF LESINURAD, A NOVEL URIC ACID REABSORPTION INHIBITOR FOR THE TREATMENT OF GOUT}

M.A. Becker ${ }^{1}$, R.T. Keenan ${ }^{2}$, P.P. Khanna ${ }^{3}$, R. Malamet ${ }^{4}$, K. Bos ${ }^{4}, \mathrm{~J} \mathrm{Li}^{4}$ J. Hu ${ }^{5}$, W.B. White ${ }^{6} .{ }^{1}$ University of Chicago, Chicago; ${ }^{2}$ Duke University School of Medicine, Durham; ${ }^{3}$ University of Michigan, Ann Arbor; ${ }^{4}$ AstraZeneca Pharmaceuticals, Wilmington; ${ }^{5}$ Formerly Ardea Biosciences, Inc, San Diego ${ }^{6}$ University of Connecticut School of Medicine, Farmington, United States

Background: Lesinurad is a selective uric acid reabsorption inhibitor recently approved at $200 \mathrm{mg}$ daily in combination with a xanthine oxidase inhibitor (XOI) for treatment of hyperuricemia associated with gout in patients who have not achieved target serum uric acid on an XOI (allopurinol or febuxostat) alone.

Objectives: To investigate the safety profile of lesinurad (LESU), we integrated safety data based on: (1) 3 large, pivotal, placebo-controlled, 12-month phase III (core) trials evaluating LESU $200 \mathrm{mg}$ and LESU $400 \mathrm{mg}$ in combination with an $\mathrm{XOI}$; and (2) 2 extension studies, in which LESU-treated patients continued to receive $\mathrm{LESU}+\mathrm{XOI}$ at the same dose and initially placebo-treated patients were randomized to receive LESU $200 \mathrm{mg}$ or LESU $400 \mathrm{mg}$ in addition to the XOI provided in the preceding core trial.

Methods: Safety data were pooled from the 3 core studies and 2 12-month extension studies using descriptive statistics for patients receiving $>1$ dose of study medication. To adjust for varying treatment durations, treatment-emergent adverse events (TEAEs) are expressed as exposure-adjusted incidence rates (number of subjects with events per 100 person-years [PY]).

Results: In the core studies, adverse event rates were comparable for $\mathrm{XOI}$ alone and LESU $200 \mathrm{mg}+$ XOI groups for any TEAEs, serious TEAEs, and TEAEs leading to discontinuation (Table 1). Adverse event rates were higher with LESU $400 \mathrm{mg}+$ XOI. Major adverse cardiovascular event (MACE) rates, which included cardiovascular death, myocardial infarction, or stroke, in the core studies were 0.71 $(95 \% \mathrm{Cl} 0.15,2.08), 0.96(0.26,2.47)$, and $1.94(0.84,3.82)$ per $100 \mathrm{PY}$ for $\mathrm{XOI}$

Table 1. Pooled Analysis of Exposure-Adjusted Adverse Event Incidence Rates in 3 Piwotal Placebo-Controlled 12-Month Phase III Studies Evaluating Lesinurad $200 \mathrm{mg}$ and $400 \mathrm{mg}$ in Combination with Xanthine Oxidase Inhibitors

\begin{tabular}{|c|c|c|c|}
\hline \multirow[b]{2}{*}{ Adverse Event Category [n (rate)] } & \multirow{2}{*}{$\begin{array}{c}\text { Xol alone } \\
(\mathrm{N}=516) \\
(\text { Pr }=408.5)\end{array}$} & \multicolumn{2}{|c|}{ LESU $200 \mathrm{mg}+$ LESU $400 \mathrm{mg}$} \\
\hline & & $\begin{array}{c}x O 1 \\
(N=511) \\
(P Y=396.3)\end{array}$ & $\begin{array}{c}x O I \\
(N=510) \\
(P Y=390.5)\end{array}$ \\
\hline AMY TEAE & $363(88.9)$ & $386(97.4)$ & $407(204.2)$ \\
\hline AMY TEAE with RCTC toxicity Grade 3 or 4 & $48(118)$ & $52(13.1)$ & $67(127.2)$ \\
\hline Any TEAE possibly related to randomized study medication & $80(19.6)$ & $98(24.7)$ & $118(30.2)$ \\
\hline Any TEAE possibly related to XOI & $52(12.7)$ & $49(12.4)$ & $66(16.9)$ \\
\hline Any TEAE possibly related to prophylaxis & $\$ 2(12.7)$ & $56(14,1)$ & $61(25.6)$ \\
\hline Any serious teAE & $29(7.1)$ & $24(6.1)$ & $44(11.3)$ \\
\hline Any fatal TEAE & $0(0)$ & $2(0.5)$ & $3(0.8)$ \\
\hline AMY TEAE leading to randomized study medication discontinuation & $28(6.9)$ & $32(8.1)$ & $48(12.3)$ \\
\hline
\end{tabular}

Table 2. Pooled Analysis of Exposure-Adjusted Adverse Event Incidence Rates in 3 Piwotal Placebo-Controlled 12-Month Phase III Studies +2 Extension Studies Evaluating Lesinurad $200 \mathrm{mg}$ and $400 \mathrm{mg}$ in Comblnation with Xanthine Oxidase Inhibitors

\begin{tabular}{|c|c|c|}
\hline Adverse Event Category [n (rate)] & $\begin{array}{c}\text { LESU } 200 \mathrm{mg} \\
+\times 01 \\
(\mathrm{~N}=666) \\
(\mathrm{PY}=926.5)\end{array}$ & $\begin{array}{c}\text { LESU } 400 \mathrm{mg} \\
\mathrm{XO1} \\
(\mathrm{N}=666) \\
(p Y=917.9)\end{array}$ \\
\hline ANY TEAE & $531(57.3)$ & $552(60.1)$ \\
\hline Any TEAE with RCTC toxicity Grade 3 of 4 & $93(10.0)$ & $115(12.5)$ \\
\hline Any TEAE possibly related to randomized study medication & $158(17.1)$ & $287(20.4)$ \\
\hline Any TEAE possibly related to $X O l$ & $n[8.3\}$ & $101(11.0)$ \\
\hline AWy TEAE possibly related to prophylaxis & $76[8.2\rceil$ & $81(8.8)$ \\
\hline Any serious TEAE & $63(6.8)$ & $84(9.2)$ \\
\hline Any fatal TEAE & $7(0.8)$ & $7(0.8)$ \\
\hline Any TEAE leading to randomized study medication discontinuation & $68(7.3)$ & $86(9.4)$ \\
\hline
\end{tabular}


alone, LESU $200 \mathrm{mg}+\mathrm{XOI}$, and LESU $400 \mathrm{mg}+\mathrm{XOI}$, respectively. Renal-related TEAE rates in the core studies were $5.6,7.3$, and 15.4 per 100 PY, respectively. Longer exposure in the core + extension studies did not result in increases in any TEAEs, serious TEAEs, or TEAEs leading to discontinuation (Table 2). MACE rates were low in the core + extension studies, at $1.05(95 \% \mathrm{Cl} 0.50,1.93)$ and $1.48(0.81,2.48)$ in the LESU $200 \mathrm{mg}+\mathrm{XOI}$ and LESU $400 \mathrm{mg}+\mathrm{XOI}$ groups, respectively. Renal events in the core + extension studies were lower in the LESU $200 \mathrm{mg}+\mathrm{XOI}$ than LESU $400 \mathrm{mg}+\mathrm{XOI}$ group at 8.6 and 14.6 , respectively. Conclusions: Lesinurad at the approved dose of $200 \mathrm{mg}$ once daily demonstrated a consistent, acceptable safety profile. There were no new safety concerns in the extension studies.

Acknowledgements: This study was funded by Ardea Biosciences/AstraZeneca. Disclosure of Interest: M. Becker Grant/research support from: Takeda, Savient, Ardea/AstraZeneca, Consultant for: Takeda, Savient, Horizon, Ardea/AstraZeneca, CymaBay, Pfizer, R. Keenan Consultant for: AstraZeneca, Ironwood, Horizon, P. Khanna Grant/research support from: AstraZeneca, R. Malamet Employee of: AstraZeneca, K. Bos Employee of: AstraZeneca, J. Li Employee of: AstraZeneca, J. Hu Employee of: Ardea Biosciences, W. White Consultant for: AstraZeneca

DOI: 10.1136/annrheumdis-2017-eular.3674

\section{THU0445 GOUTY ARTHRITIS: DECISION MAKING FOLLOWING DUAL ENERGY CT SCAN IN CLINICAL PRACTICE, A RETROSPECTIVE ANALYSIS}

M. Gamala ${ }^{1}$, S. Linn-Rasker ${ }^{2}$, M. Nix ${ }^{2}$, B. Heggelman ${ }^{2}$, J. van Laar ${ }^{1}$ P. Pasker-de Jong ${ }^{2}$, J. Jacobs ${ }^{1}$, R. Klaasen ${ }^{2} .{ }^{1}$ University Medical Center, Utrecht: ${ }^{2}$ Meander Medical Centre, Amersfoort, Netherlands

Background: Gout is associated with joint damage, and increased cardiovascular morbidity; it is important to diagnose and treat it. However, although clinical presentation may be strongly suggestive of gout, joint aspiration and microscopy not always yield the diagnosis. The latest technique to visualize monosodium uric acid MSU depositions and thus to diagnose gout is Dual Energy CT scan (DECT). ${ }^{1}$

Objectives: To establish whether DECT is a diagnostic tool, i.e. associated with initiation or discontinuation of a urate lowering drug (ULD). Second, whether DECT results (gout deposition $\mathrm{y} / \mathrm{n}$ ) can be predicted by clinical and laboratory variables.

Methods: Digital medical records of 147 consecutive patients with clinical suspicion of gout at the outpatient clinic of the Department of Rheumatology of Meander Medical Centre, Amersfoort, the Netherlands who underwent DECT between January 1, 2013 and December 31, 2014 were analyzed retrospectively. Collected were clinical data including medication before and after DECT, lab results, and results from diagnostic joint aspiration and DECT. The relationship between DECT results and clinica, and laboratory results was evaluated by univariate regression analyses; predictors showing a $p<0.10$ were entered in a multivariate logistic regression model with the DECT result as outcome variable. A manual backward stepwise technique was applied.

Results: 87 patients were diagnosed with gout based on demonstration of MSU crystals in synovial fluid (SF) or positive DECT result. In 30 patients, DECT was the only conformation of gout; in 29 of them ULD was started and in 1 it was intensified. Following DECT, the current ULD was stopped in 3 patients. The clinical and laboratory variables associated with the DECT result are presented in table 1. In the multivariable regression model, cardiovascular disease $\mathrm{y} / \mathrm{n}$ (OR $3.07,95 \% \mathrm{Cl} 1.26-7.47$ ), disease duration in years (OR 1.008, 95\% Cl 1.0011.016), frequency of attack per year (OR $1.23,95 \% \mathrm{Cl} 1.07-1.42$ ), creatinine clearance in $\mathrm{ml} / \mathrm{min}(\mathrm{OR} 2.03,95 \% \mathrm{Cl} 0.91-1.00)$ were independently associated with positive DECT results.

Table 1. Univariate model analyses of predictors of positive DECT results

\begin{tabular}{lcc}
\hline & OR $(95 \% \mathrm{Cl})$ & $\mathrm{p}$ \\
\hline Gender (reference: male gender) & $0.48(0.24-0.99)$ & 0.04 \\
Body Mass Index (per $\left.\mathrm{kg} / \mathrm{m}^{2}\right)$ & $1.03(0.96-1.11)$ & 0.36 \\
Cardiovascular disease yes/no & $2.72(1.36-5.42)$ & 0.04 \\
Diabetes mellitus yes/no & $3.69(1.26-10.71)$ & 0.01 \\
Urate lowering therapy use at the moment of DECT yes/no & $2.6(1.15-6.28)$ & 0.02 \\
Disease duration years & $1.01(1.005-1.02)$ & 0.01 \\
Frequency of attacks per year & $1.2(1.08-1.33)$ & 0.01 \\
Uric acid levels between flares (per $\mu \mathrm{mol} / \mathrm{L})$ & $1.004(1.001-1.007)$ & 0.008 \\
Creatinine clearance $($ per $\mathrm{ml} / \mathrm{min})$ & $0.95(0.92-0.99)$ & 0.01 \\
Joint involvement at the moment of DECT: MTP1 or other joints & $1.69(1.05-3.37)$ & 0.1 \\
Past first metatarsophalangeal (MTP1) joint involvement yes/no & $3.37(1.69-6.72)$ & 0.01 \\
MSU crystals at microscopy yes/no & $1.62(1.23-2.17)$ & 0.001 \\
\hline
\end{tabular}

Conclusions: DECT has impact on clinical decisions on ULD therapy. It may be a useful diagnostic imaging tool for patients who cannot undergo joint aspiration because of contraindications or with difficult to aspirate joints, or those who refuse joint aspiration.

References:

[1] Choi HK et al. Dual energy CT in gout: a prospectieve validation study. Ann Rheum Dis 2012; 71:1466-71.

Disclosure of Interest: None declared

DOI: 10.1136/annrheumdis-2017-eular.1881

\section{THU0446 PREVALENCE AND INCIDENCE OF NON-GOUT CRYSTAL ARTHROPATHY IN SOUTHERN SWEDEN FROM THE SOCIOECONOMIC PERSPECTIVE}

M. Hameed ${ }^{1}$, A. Turkiewicz ${ }^{2}$, T. Saxne ${ }^{3}$, L. Jacobsson ${ }^{4}$, M. Englund ${ }^{5}$, M.C. Kapetanovic ${ }^{6} .{ }^{1}$ Department of Clinical Sciences, Lund, Section for Rheumatology, Lund University, Lund and Skåne University Hospital, Section for Rheumatology in Lund and Malmö, Sweden, Malmö; ' 2 Lund University, Faculty of Medicine, Department of Clinical Sciences Lund, Orthopedics, Clinical Epidemiology Unit, Lund, Sweden; ${ }^{3}$ Department of Clinical Sciences, Lund, Section for Rheumatology, Lund University, Lund, Section for Rheumatology in Lund and Malmö, Lund; ${ }^{4}$ Department of Rheumatology \& Inflammation Research, Institute of Medicine, The Sahlgrenska Academy, University of Gothenburg, Gothenburg; ${ }^{5}$ Lund University, Faculty of Medicine, Department of Clinical Sciences Lund, Orthopedics, Clinical Epidemiology Unit; ${ }^{6}$ Department of Clinical Sciences, Lund, Section for Rheumatology, Lund University, Lund and Skåne University Hospital, Section for Rheumatology in Lund and Malmö, Sweden, Lund, Sweden

Background: Recently, we reported the prevalence of gout to be $1.7 \%$ among adults in the Skåne region in southern Sweden (1). Few epidemiological data are available on non-gout crystal arthropathy and none for this region.

Objectives: The objective of this study was to study the prevalence and incidence of non-gout crystal arthropathy (including chondocalcinosis, acute/subacute/chronic calcium pyrophosphate/hydroxyapatite or other crystal deposition disease) in southern Sweden from the socioeconomic perspective. Methods: The Skåne Healthcare Register includes information on all health care visits with given ICD10-coded diagnoses for all citizens in the region (total population 1.3 million). SHR was searched for all adult ( $\geq 18$ years) residents in Skåne region in year 2014, who between 1998 and 2014 had received at least one diagnosis of non-gout crystal arthropathy (ICD-10 code M11.0- M11.9) by any physician. The crude point prevalence at December 31st 2014 and the cumulative incidence in the calendar year 2014 were calculated. In addition, we examined the 2014 age- and sex- standardized point prevalence and cumulative incidence of non-gout crystal arthropathy according to occupation (white collar /blue collar with high or low skilled occupations), income (low/middle/high) and level of education (primary school/high school/university).

Results: The crude 2014 point prevalence and 2014 cumulative incidence $(95 \% \mathrm{Cl})$ of non-gout crystal arthropathy were $0.23 \%(0.22 \%-0.24 \%)$ and 21.5 (18.6-24.3) cases per 100000 persons at risk, respectively. Compared to women, men had numerically but not significantly higher prevalence $(0.26 \%$ vs $0.20 \%$ ) and incidence (24.6 vs 18.5 per 100000 persons). This pattern remained regardless of age. The mean (SD) age of a person with prevalent non-gout crystal arthropathy was 71.5 (14.4) years. Both prevalence and incidence increased with increasing age and were highest in individuals $>85$ years (prevalence $1.4 \%$ ), but decreased with years of education. Persons with middle income and blue collar high skilled occupation (e.g. skilled agricultural, forestry and fishery workers and craft and related trades workers) had the highest point prevalence and incidence of non-gout crystal arthroplasty (figure).
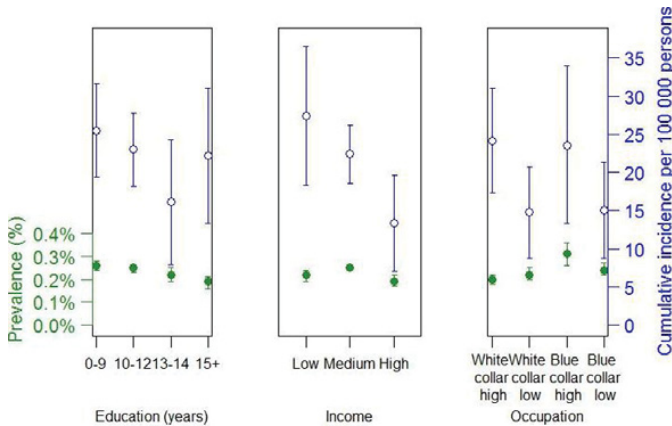

Conclusions: Although considerably less prevalent than gout in southern Sweden non-gout crystal arthropathy affects about $0.2 \%$ of the adult population, i.e. a similar prevalence as for psoriatic arthritis in the same region. The prevalence increases with age and is highest among individuals aged 85 years or higher. There is a socioeconomic gradient with more affected individuals among people with lower level of education, middle income, and more manual work.

References:

[1] Kapetanovic MC, Hameed M, Turkiewicz A, at al. Prevalence and incidence of gout in southern Sweden from the socioeconomic perspective. RMD Open. 2016 Nov 1;2(2):e000326. eCollection 2016.

Disclosure of Interest: None declared

DOI: 10.1136/annrheumdis-2017-eular.3089 